This is the final draft post-refereeing.

The publisher's version can be found at http://dx.doi.org/10.1016/j.chroma.2015.08.070

Please cite this article as: Lambrecht, M. A.; Rombouts, I.; Van Kelst, L.; Delcour, J. A. Impact of extraction and elution media on non-size effects in size exclusion chromatography of proteins. Journal of Chromatography A. 2015, 1415, 100-107.

\title{
Impact of extraction and elution media on non-size effects in size exclusion chromatography of proteins
}

Marlies A. Lambrecht*, Ine Rombouts, Lotte Van Kelst, Jan A. Delcour Laboratory of Food Chemistry and Biochemistry and Leuven Food Science and Nutrition Research Centre (LFoRCe), KU Leuven, Kasteelpark Arenberg 20, B-3001 Leuven, Belgium

*Corresponding author, Tel.: +32 16 376781; fax: +32 16321997.

E-mail address: marlies.lambrecht@biw.kuleuven.be

\section{Abstract}

2 Size exclusion chromatography is extensively used to separate proteins and to determine their apparent molecular weights. It separates proteins based on hydrodynamic volume, but interactions between the chromatography resin and proteins lead to non-size effects. This report discusses the impact of co-solvents [salt, urea, sodium dodecyl sulfate (SDS), dithiothreitol] in extraction media when separating wheat gluten proteins, soy glycinin, bovine serum albumin and ovalbumin on a Biosep-SEC-S4000 column. With acetonitrile/water $(1: 1, \mathrm{v} / \mathrm{v})$ containing $0.05 \%(\mathrm{v} / \mathrm{v})$ trifluoroacetic acid as eluent, salts and SDS in the extraction media increase while urea decreases non-size effects. Most gluten and globular proteins are extractable in sodium phosphate buffer (0.050 M; pH 6.8) containing $2.0 \%(\mathrm{w} / \mathrm{v})$ SDS. This chromatographic medium allows analyzing mixtures of various proteins without any non-size effects.

Key words

\section{Introduction}


Size exclusion (SE) chromatography is widely used in biology, biochemistry, (food) chemistry and pharmacology to purify proteins and to study their apparent molecular weight (MW) [1] and aggregation [2]. Ideally, SE high performance liquid chromatography (SE-HPLC) elutes proteins in order of decreasing hydrodynamic volume, and thus size [3]. However, hydrogen, ionic, hydrophobic and Van der Waals interactions between chromatographic resins and proteins can occur, sometimes even followed by protein conformational changes [4-6]. Such non-ideal interactions lead to non-size effects including changes in elution time, chromatographic resolution, peak shape and even level of detected protein [7]. Furthermore, they can weaken non-covalent interactions between proteins thereby hampering the quantification of non-covalently associated protein aggregates [4]. In some cases, non-size effects are helpful. For instance, Ovalle [8] separated proteins with similar MW but different isoelectric points on a SE column using a zwitterionic buffer. Either way, it is of the utmost importance to be well informed of potential non-size effects.

The level of interactions between proteins and resins depends on the resin type, the proteins involved and the mobile phase [7]. Two types of SE resins can be distinguished namely (i) inorganic materials based on silica particles coated with a hydrophilic outer layer and (ii) organic polymeric cross-linked particles with a more hydrophobic character [9]. In this study silica-based resins of welldefined pore-size distribution are used. These resins are rigid, stable towards a variety of mobile phases between pH 2 and 8 [10], and can easily be regenerated after exposure to denaturants [11]. For uncharged (electrically neutral) solutes, distilled water is a suitable eluent [12]. For albumins and globulins, non-ideal interactions can be minimized by adding co-solvents like salts, organic modifiers, detergents or amino acids to the elution solvent [4,7]. Nearly ideal SE chromatography can be executed by minimizing ionic and hydrophobic interactions which suggests minor influence of hydrogen and Van der Waals interactions [5].

The most common eluents can be divided in two types: inorganic buffers and mixtures of water with organic modifiers. For silica-based resins, inorganic buffers with an ionic strength between 0.1-0.5 M are generally used [13]. At low ionic strength, ionic interactions between resins and proteins occur $[3,14]$. Ionized silanol residues $\left(\mathrm{pK}_{\mathrm{a}}\right.$ 3.5-4.0) impart it with cation-exchange properties. They form an anionic field which interacts with proteins $[3,8]$. The addition of salts decreases the ionic interactions between resin and proteins $[4,5,8]$. However, high ionic strength can induce hydrophobic interactions due to solvophobic [3] or salting-out effects [7]. Under these conditions even slightly hydrophobic coatings can interact with proteins. When the conformations of proteins in mixtures are unknown, denaturing agents like urea or guanidinium hydrochloride, or anionic surfactants like sodium dodecyl sulfate (SDS) are often added to the extraction medium. For denatured proteins, the hydrodynamic volume, which can be deduced from its elution time, correlates well with peptide 
chain length and protein MW $[10,15,16]$. Acetonitrile (ACN) is a popular organic modifier even though it can enhance ionic interactions and at concentrations exceeding $40 \%$ induce conformational changes in proteins [17]. Trifluoroacetic acid (TFA) $(0.05 \%$ or $0.1 \% \mathrm{w} / \mathrm{v})$ is often added. It is UV transparent, can increase protein solubility and decrease non-ideal hydrophobic interactions [14]. It suppresses ionization of silanol residues $[5,18]$ but some cation-exchange capacity at low pH can remain due to ion-pairing $[5,14]$. Combinations of co-solvents can impact the intended effect. For instance, sodium chloride and ACN in the elution solvent counterbalance each other's non-size effects [4]. The combination of other co-solvents and their impact on non-size effects remain to be investigated.

The above shows that non-size effects in SE-HPLC have gained more attention over the last years in different contexts [2,4]. SE-HPLC is e.g. also useful for evaluating changes in protein MW during food processing [19], but the study of non-size effects in this context is more complex. A food protein mixture which contains albumins and globulins which are completely extractable in water can be analyzed with water as extraction and elution medium. Nevertheless, most food systems are more complex and contain more different protein types. In some food products, e.g. pastry, bread, noodles and pasta, cereal proteins can coexist with egg, soy or milk proteins. All these protein types can codetermine food properties such as texture. In contrast to albumins and globulins which have already been studied in the context of non-size effects, cereal storage proteins, i.e. glutelins and prolamins, are mostly insoluble in water and salt solutions and non-size effects impacting these proteins remain to be investigated. To evaluate heat-induced changes in $\mathrm{MW}$ of cereal proteins, extraction is often performed in SDS containing media [20-22]. It is unclear whether SDS and other co-solvents in extraction media impact non-size effects. Even though concentrations are low, co-solvents in extraction media can impact both protein conformation and column properties.

Against this background, we here optimized an SE-HPLC method for studying various protein types present in food. SDS containing media extract almost all protein from cereals, milk, eggs and soy. The first aim was to investigate the impact of elution solvent on non-size effects between a silica-based resin and proteins extracted in SDS containing media. The second aim was to study non-size effects for various combinations of extraction media and elution solvents.

\section{Materials and methods}

\subsection{Materials}

Wheat kernels (cultivar Paragon) from RAGT (Ickleton, United Kingdom) were conditioned to $16.0 \%$ moisture and milled with a Bühler (Uzwil, Switzerland) MLU-202 laboratory mill to obtain wheat flour 
with $13.7 \%$ protein on dry matter $(\mathrm{dm})$ basis. Gluten $(83.2 \% \mathrm{dm}$ protein) was isolated from flour with a dough ball method. Flour ( $98.6 \mathrm{~g}, 12.5 \%$ moisture) was mixed with $55.0 \mathrm{ml}$ deionized water in a pinmixer (National Manufacturing, Lincoln, NE, USA) for $150 \mathrm{~s}$ to form an optimal dough as estimated by a mixograph (National Manufacturing, AACC I Approved Method 54-40.02 [23]). After a dough rest of $60 \mathrm{~min}$, gluten was separated from dough by washing with deionized water (ca. $1000 \mathrm{ml}$ ). The fraction above $38 \mu \mathrm{m}$ is called gluten. Soy glycinin ( $98.1 \% \mathrm{dm}$ protein) was extracted according to Liu et al. [24] from soy flour (L.I. Frank, Twello, The Netherlands). Gluten and soy glycinin were freeze dried and ground in a laboratory mill (IKA, Staufen, Germany). Gluten was passed through a $250 \mu \mathrm{m}$ sieve. Bovine serum albumin (BSA, fraction V for biochemistry) was from Acros Organics (Geel, Belgium) and contained $98.2 \% \mathrm{dm}$ protein. Ovalbumin (albumin chicken egg grade III) was purchased from Sigma-Aldrich (Bornem, Belgium) and contained $94.1 \% \mathrm{dm}$ protein. All chemicals were at least of analytical grade and from Sigma-Aldrich unless specified otherwise. Urea, dithiothreitol (DTT), disodium hydrogen phosphate and sodium dihydrogen phosphate were from VWR International (Leuven, Belgium).

\subsection{Protein content determination}

Protein contents of gluten, glycinin, BSA and ovalbumin samples and their extracts were determined in triplicate using an adaptation of the AOAC Official Method 990.03 [25], with an automated Dumas protein analysis system (EAS Variomax N/CN, Elt, Gouda, The Netherlands). Conversion factors (5.7 for wheat flour and gluten; 6.25 for soy glycinin, BSA and ovalbumin) were used to calculate protein from nitrogen contents.

\subsection{Size-exclusion HPLC}

Proteins (1.0 $\mathrm{mg}$ protein $/ \mathrm{ml}$ extraction medium) from gluten, soy glycinin, BSA and ovalbumin samples were extracted/dissolved (60 min, room temperature) with different media: water, sodium phosphate medium (0.050 M; pH 7.6) with $0.4 \mathrm{M}$ sodium chloride, hereafter referred to as salt medium, or sodium phosphate buffer $(0.050 \mathrm{M}$; pH 6.8) containing (i) $2.0 \%(\mathrm{w} / \mathrm{v})$ SDS, further referred to as SDS medium, (ii) $2.0 \%(\mathrm{w} / \mathrm{v})$ SDS with $2.0 \mathrm{M}$ urea, (iii) $2.0 \%(\mathrm{w} / \mathrm{v})$ with $1.0 \%(\mathrm{w} / \mathrm{v})$ DTT and (iv) $2.0 \%(\mathrm{w} / \mathrm{v}$ ) SDS with $2.0 \mathrm{M}$ urea and $1.0 \%(\mathrm{w} / \mathrm{v}$ ) DTT (Table 1). When the extraction medium contained DTT, the extraction was performed under nitrogen atmosphere. All extractions were in triplicate and followed by centrifugation $(10000 \mathrm{~g}, 10 \mathrm{~min}$ ) and filtration (Millex-HP, $0.45 \mu \mathrm{m}$, polyethersulfone; Millipore, Carrigtwohill, Ireland). SE-HPLC was conducted using a LC-2010 system (Shimadzu, Kyoto, Japan) with automated injection monitoring at $214 \mathrm{~nm}$. Protein extracts were loaded on a Biosep-SEC-S4000 column (pore size $500 \AA$, Phenomenex, Torrance, CA, USA). Injection 
volume was $60 \mu \mathrm{l}$ unless specified otherwise. Elution media (flow rate $1.0 \mathrm{ml} / \mathrm{min}, 30^{\circ} \mathrm{C}$ ) were (i) ACN/water $(1: 1, \mathrm{v} / \mathrm{v})$ containing $0.05 \%(\mathrm{v} / \mathrm{v})$ TFA $(\mathrm{pH} 2.25$ after correction for measurements in $\mathrm{ACN} /$ water mixtures [26]), (ii) SDS medium and (iii) $0.100 \mathrm{M}$ sodium phosphate buffer (pH 6.8) with $2.0 \%(\mathrm{w} / \mathrm{v})$ SDS. The relative area was calculated from the peak area expressed as a percentage of the area of proteins extracted in SDS/urea/DTT medium. After analyses where SDS was a component of the eluent, the column was cleaned overnight with water to avoid SDS contamination. No irreversible modification of the Biosep-SEC-S4000 column performance as a result of the use of SDS was noticed.

\subsection{Protein extractability}

Proteins (10 $\mathrm{mg}$ protein/ml extraction medium) from gluten, soy glycinin, BSA and ovalbumin samples were extracted/dissolved and centrifuged as in section 2.3. The protein contents of the supernatants of these extracts were then determined as in section 2.2. Protein extractability was defined as the percentage of the protein content of an extract relative to the total protein content.

\subsection{Lab-on-a-Chip capillary electrophoresis}

To approximately $7.0 \mathrm{mg}$ of BSA or ovalbumin, $1.0 \mathrm{ml}$ SDS medium was added and samples were shaken (30 $\mathrm{min}$, room temperature). After centrifugation (13000 g, $10 \mathrm{~min}$ ), $8 \mu$ l supernatant was mixed with $4 \mu \mathrm{l}$ of Agilent sample buffer (Agilent Technologies, Santa Clara, CA, USA) and heated at $100^{\circ} \mathrm{C}$ for $5.0 \mathrm{~min}$. After cooling, $168 \mu \mathrm{l}$ deionized water was added. The mixture $(6 \mu \mathrm{l})$ and $\mathrm{MW}$ markers were applied on an Agilent LabChip of a protein 230 kit and analyzed with an Agilent 2100 Bioanalyzer system to obtain electrophoresis patterns.

\subsection{Statistics}

Linear regression was used to determine slopes, intercepts and standard errors of calibration curves. Slopes were compared with an ANCOVA test $(\mathrm{P}<0.05)$ using JMP ${ }^{\circledR}$ Pro 11.2.0 (SAS institute, Cary, NC, USA).

\section{Results and discussion}

\subsection{Non size effects on proteins extracted/dissolved in SDS containing medium}

SDS medium yields high extraction/solubility levels of various protein types without breaking covalent bonds (Table 2). Here, the impact of elution media on non-size effects for proteins extracted/dissolved in SDS medium was investigated. 
First, BSA, ovalbumin and gluten proteins were extracted with SDS medium (1 $\mathrm{mg}$ protein per $\mathrm{ml}$ ) and chromatographically separated with $\mathrm{ACN} /$ water $(1: 1, \mathrm{v} / \mathrm{v})$ containing $0.05 \%(\mathrm{v} / \mathrm{v})$ TFA as elution medium, i.e. a typical eluent for both globular [27] and cereal [22] proteins. Total UV absorbance was fitted as a function of injected extractable protein (Table 3). The formula by Kuipers and Gruppen [28] shows that the absorbance at $214 \mathrm{~nm}$ per mass unit protein is almost equal for BSA, ovalbumin and gluten protein. Nevertheless, the slopes of the calibration curves were higher for BSA and gluten than for ovalbumin (Table 3; ANCOVA test with $\alpha=0.05$ ). Ovalbumin was underestimated. In addition, the resolution of the SE profile was poor (Figure 1.A). Ovalbumin either interacted with the column or precipitated in ACN/water $(1: 1, \mathrm{v} / \mathrm{v})$ containing $0.05 \%(\mathrm{v} / \mathrm{v})$ TFA. To investigate the likelihood of these phenomena, the ovalbumin extract was injected $(2 \mu \mathrm{l})$ over the bypass, i.e. not separated over the column, using either ACN/water $(1: 1, \mathrm{v} / \mathrm{v})$ containing $0.05 \%(\mathrm{v} / \mathrm{v})$ TFA or SDS medium as elution solvent. The total absorbance in ACN/water was $96 \%$ of that in SDS medium. Thus, ovalbumin precipitation in the eluent was limited - if any. Instead, ovalbumin underestimation was mainly caused by interactions between the protein and the column. SE profiles of BSA showed three peaks (Figure 1.A) while Lab-on-a-Chip electrophoresis only revealed dimers and monomers (Figure 2.A). The partial postponed elution of BSA was a non-size effect (Figure 1.A). For gluten proteins, no nonsize effects were noted. SDS-extractable glutenin eluted between $5 \mathrm{~min}$ and $6 \mathrm{~min} 40 \mathrm{sec}$, gliadin between $6 \mathrm{~min} 40 \mathrm{sec}$ and $8 \mathrm{~min} 5 \mathrm{sec}$. Each protein has a unique pattern of surface charge distribution and hydrophobicity [29]. Dubin et al. [29] demonstrated that not the net protein charge but the mean surface potential determines interactions of proteins with the resin.

Next, SDS medium was used both as extraction/solubilizing and elution medium. BSA mainly eluted as monomer at $8 \mathrm{~min} 40 \mathrm{sec}$, and partly as dimer at $7 \mathrm{~min} 40 \mathrm{sec}$ (Figure 1.B) in agreement with Labon-a-Chip electrophoresis observations (Figure 2.A). Ovalbumin monomers and dimers, also observed by Lab-on-a-Chip electrophoresis (Figure 2.B), eluted at respectively $8 \mathrm{~min} 55 \mathrm{sec}$ and $7 \mathrm{~min}$ $55 \mathrm{sec}$ (Figure 1.B). Low levels of proteins eluted at $10 \mathrm{~min} 25 \mathrm{sec}$ probably due to sample contamination ( $\geq 90 \%$ purity). SDS-extractable glutenin eluted between $5 \mathrm{~min}$ and $7 \mathrm{~min} 55 \mathrm{sec}$ and gliadin between $7 \mathrm{~min} 55 \mathrm{sec}$ and $9 \mathrm{~min} 36 \mathrm{sec}$ (Figure 1.B). No indications for non-size effects were noted. Proteins eluted as expected based on their MWs. In contrast to what was the case with the first elution medium, the slopes of the calibration curves of BSA, ovalbumin and gluten were not significantly different (Table 3; ANCOVA test: $P$ > 0.05). However, the calibration curve of BSA was only linear up until $0.030 \mathrm{mg}$ protein, while those of gluten and ovalbumin were linear up until 0.100 $\mathrm{mg}$ and $0.080 \mathrm{mg}$ protein respectively. The slopes of the calibration curves of BSA and gluten were slightly higher with SDS medium as eluent than with ACN/water $(1: 1, \mathrm{v} / \mathrm{v})$ containing $0.05 \%(\mathrm{v} / \mathrm{v})$ TFA 
Increasing the sodium phosphate concentration in the SDS medium from $0.050 \mathrm{M}$ to $0.100 \mathrm{M}$ decreased the absorbance per mass unit injected extractable protein BSA and gluten by respectively 49\% and 59\% (results not shown). Even after injection over the bypass, it already decreased the absorbance per mass unit injected extractable protein with $c a .33 \%$ and $c a .11 \%$ for BSA and gluten, respectively. Even though eluents usually have a salt concentration between 0.10 and $0.50 \mathrm{M}$ [13], our results show that such salt concentrations induced salting-out of proteins extracted in SDS medium. Salting out occurred as soon as the protein extracts were immersed in elution solvent, but even more during separation on column.

With ACN/water $(1: 1, \mathrm{v} / \mathrm{v})$ containing $0.05 \%(\mathrm{v} / \mathrm{v})$ TFA as eluent, all protein levels were (slightly) underestimated and BSA elution was postponed. No non-size effects were noted for any protein analyzed using SDS medium as extraction/solubilizing medium and eluent. The linear range depended on the protein. It was highest for gluten and lowest for BSA. Increasing the concentration of salt in the eluent caused salting out of all tested proteins.

\subsection{Impact of extraction/solubilizing media on non-size effects with acetonitrile-water as eluent}

This section investigated the impact of extraction media (Table 1) on non-size effects when ACN/water (1:1, v/v) containing $0.05 \%(v / v)$ TFA was used as eluent (Figures 3.A1 to 3.A5, Table 4) to increase the insight of co-solvents in extraction media and their working mechanisms on the separation of proteins. With this eluent, non-size effects were noted for proteins extracted in SDS medium (cfr. Section 3.1).

The peak shapes for BSA and ovalbumin extracted in water did not reveal non-size effects (Figure 3.A1). However, BSA (66 kDa) and ovalbumin ( $43 \mathrm{kDa}$ ) eluted at the same time as glutenin (> $80 \mathrm{kDa})$ extracted with SDS medium (Figure 1.A) which is earlier than expected based on their MWs. At pH 2.25, silanol residues of the resin have a net positive charge [5]. Thus, in aqueous media repulsive ionic interactions decrease the affinity of BSA ( $p l 4.7)$ and ovalbumin ( $p l 4.5)$ for the resin. From the gluten and flour samples, only albumins were extractable in water (Tables 2 and 4). Profiles of albumins extracted from the gluten sample in water were not shown in Figure 3.

As salts lower ionic interactions, their inclusion in the extraction medium reduced the repulsion between negatively charged proteins and the column. The salts shifted the monomer peak of BSA from $6.2 \mathrm{~min}$ in water to $6.4 \mathrm{~min}$ (Figure 3.A2). However, salts had a huge negative impact on separation and detection (Table 4) of BSA and ovalbumin. Part of BSA eluted later than the remainder. The ovalbumin level was underestimated (Tables 2 and 4). At low pH (here 2.25), salts can induce denaturation, i.e. unfolding of proteins with loss of secondary and tertiary structure [30], and 
thereby increase the affinity of proteins for resins. In addition, at low ionic strength salts can bind as counter ions and reduce repulsive interactions between resin and protein [31]. Thus, more non-size effects occurred in salt medium than in water, and they were caused both by ionic and hydrophobic interactions.

For globular proteins, e.g. BSA, ovalbumin and soy glycinin extracted in SDS medium, the same nonsize effects occurred as in salt medium but more prominently (Figure 1.A). The anionic detergent SDS binds proteins reversibly through hydrophobic and ionic interactions [32]. It strongly interacts with oppositely charged globular proteins [33] like ovalbumin and BSA at pH 2.25. By giving protein a negative charge, it increases its affinity for the positively charged resin resulting in postponed elution and even reduced detection. However, within one protein the affinity of SDS differs for various sites [32]. That only a fraction of BSA eluted later (Figure 1.A) can be explained by the different degrees of denaturation of both secondary and tertiary structures induced by SDS binding to various protein sites. SDS increased the extractability of soy glycinin and gluten proteins by breaking non-covalent interactions (Table 3). While SDS was essential for extracting gluten proteins, it caused non-size effects for globular proteins by disrupting their structure.

The inclusion of urea in SDS medium decreased non-size effects for BSA and ovalbumin (Figure 3.A3 and Figure 1.A). It minimized the shift of BSA to higher retention times and increased the total area of ovalbumin (Table 4). SDS and urea interact with different protein sites [32]. While urea unfolds proteins, reduces the $\alpha$-helicity and completely disrupts $\beta$-structures [34], the impact of SDS on the conformation of globular proteins depends on the presence of urea [35,36]. In its absence, SDS reduces the $\alpha$-helicity of native BSA. In its presence, SDS can induce some non-native secondary structure $[35,36]$. These differences in secondary structure probably alter the affinity for resins. Furthermore, urea may occupy protein binding sites which otherwise would be available for binding with resins. The use of urea increased the extractability of proteins from wheat flour and gluten (Table 4), more specifically that of glutenin (Figure 3.A3). No non-size effects for wheat flour and gluten were noted.

The inclusion of DTT in SDS medium increased the portion of BSA which eluted later (Figure 3.A4). In absence of DTT, SDS decreases the $\alpha$-helical structure of BSA but conserves some secondary structure [37]. Interactions of SDS with BSA are restricted as a result of its 17 disulfide bonds. When these are broken, BSA unfolds to a larger extent leading to sites which are better accessible for interactions with the column. For ovalbumin, SDS/DTT medium had no profound impact on peak distribution but slightly decreased the level of protein detected (Figure 3.A4). That ovalbumin has only one disulfide bond [38] may explain why DTT did not increase non-size effects for ovalbumin to 
the same extent as for BSA. With DTT, areas of extracts from wheat flour or gluten increased and more protein eluted later (Figure 3.A4). The reduction of disulfide bonds between glutenin subunits increased the extractability of wheat flour and gluten proteins, as reflected in Table 4.

247

Under reducing conditions, inclusion of urea in SDS medium had the same impact as that under nonreducing conditions. It minimized the shift of BSA to higher retention times and increased the quantity of ovalbumin detected (Figure 3.A5, Table 4). The reduction of disulfide bonds in BSA and ovalbumin shifted their profiles to lower elution times due to their increased hydrodynamic volumes. Remarkably, DTT did not reduce all BSA and ovalbumin dimers. While SDS/DTT medium increased non-size effects for ovalbumin and BSA, SDS/urea/DTT medium had little impact on SE profiles. Urea and SDS bind with different regions during protein unfolding [32], reducing the affinity for resins. Furthermore, some non-native secondary structure is created when both SDS and urea are present, even after reduction of disulfide bonds, thereby minimizing non-size effects. SDS/urea/DTT medium had the same impact on the SE profile of gluten as did SDS/DTT medium. It decreased the average MW and increased total detected area.

To conclude, with ACN/water $(1: 1, \mathrm{v} / \mathrm{v})$ containing $0.05 \%(\mathrm{v} / \mathrm{v})$ TFA as eluent proteins did not elute as expected based on their MW. Repulsive ionic interactions between the column and globular proteins extracted in water decreased their elution time. Salts in the extraction medium induced protein denaturation thereby improving the affinity for resins through both ionic and hydrophobic interactions. All globular proteins and most of the gluten proteins were extractable in SDS medium. However, non-size effects on globular proteins were even more pronounced in SDS than in salt medium due to the enhanced unfolding. Addition of urea to SDS medium reduced non-size effects on globular proteins. Urea probably occupies protein binding sites on the resin and induces some nonnative secondary structure. DTT increased non-size effects on globular proteins. No non-size effects were noted for gluten proteins based on their SE profiles.

\subsection{Impact of extraction/solubilizing media on non-size effects with SDS containing medium as eluent}

Figures 3.B1 to $3 . B 5$ show the SE profiles of BSA, ovalbumin and gluten extracted in various media (Table 1) and separated with SDS medium as eluent. A better resolution was obtained for all proteins than with ACN/water (1:1, v/v) containing $0.05 \%$ (v/v) TFA as eluent (Figure 3).

Extracts of BSA and ovalbumin in water eluted as dimers and monomers (Figure 3.B1). Contamination of the commercial ovalbumin sample eluted at $10 \mathrm{~min} 20 \mathrm{sec}$. Addition of salts increased the elution times (Figure 3.B2). With SDS medium as eluent, ionized silanol residues repelled BSA and ovalbumin 
which also have a net negative charge at $\mathrm{pH}$ 6.8. Salts minimized ionic interactions. By shielding they increased the affinity of ovalbumin and BSA for the resin and hence the elution time. Nevertheless, salts in the extraction medium deteriorated neither separation nor detection.

With SDS medium as eluent, extracts of ovalbumin and BSA in SDS medium (Figure 1.B) resulted in SE profiles similar to those when using water as extraction medium. In SDS medium, both proteins and resin had a net negative charge. SDS/urea medium slightly increased the portion of oligomer fractions of ovalbumin and BSA but substantial differences were noted neither with regard to resolution, elution times, elution profile (Figure 3.B3) nor relative areas (Table 5).

Under reducing conditions, SE profiles of ovalbumin and BSA shifted to lower elution times (Figure 3.B4). The cleavage of intramolecular disulfide bonds made these proteins more accessible to denaturants thereby increasing their hydrodynamic volume. Remarkably, BSA and ovalbumin dimers were still present under reducing conditions. Probably, the compact structure of these proteins hindered the reduction of disulfide bonds. Inclusion of urea in SDS medium under reducing conditions impacted neither SE profiles (Figure 3.B5) nor relative areas of any protein (Table 5). This had been noted under non-reducing conditions as well.

With SDS medium as eluent, co-solvents in the extraction medium did not induce non-size effects. This method has already successfully been applied to extract and separate proteins of egg noodles, bread, pastry and cake (results not shown). Various proteins were distinguished based on elution time and heat-induced changes were monitored. Proteins with lower MW were successfully separated with good resolution on Biosep-SEC-S3000 and -S2000 columns using the same extraction and elution conditions but at a flow rate of $0.5 \mathrm{ml} / \mathrm{min}$ (results not shown).

\section{Conclusions}

This work demonstrated the importance of selecting an appropriate eluent for analyzing proteins using SE-HPLC. While albumins and globulins were completely extractable in respectively water and aqueous salt solutions, gluten proteins required an extraction medium with co-solvents such as the denaturing agent SDS. Co-solvents in extraction media impacted the separation of proteins, especially for albumins and globulins, when ACN/water mixture was the eluent. Salts and SDS increased while urea decreased non-size effects. In contrast, with SDS medium as elution solvent, cosolvents in extraction media had substantial impact on neither peak shape and resolution, protein levels, nor on elution time.

\section{Acknowledgements}


This work is part of the Methusalem programme "Food for the future" at the KU Leuven. I. Rombouts wishes to acknowledge the Research Foundation-Flanders (FWO, Brussels, Belgium) for a function as postdoctoral researcher. J. A. Delcour is W. K. Kellogg Chair in Cereal Science and Nutrition at the KU Leuven.

\section{References}

[1] R.D. Ricker, L.A. Sandoval, Fast, reproducible size-exclusion chromatography of biological macromolecules, Journal of Chromatography A 743 (1996)(1): 43-50.

[2] J.F. Carpenter, T.W. Randolph, W. Jiskoot, D.J.A. Crommelin, C.R. Middaugh, G. Winter, Potential inaccurate quantitation and sizing of protein aggregates by size exclusion chromatography: Essential need to use orthogonal methods to assure the quality of therapeutic protein products, Journal of Pharmaceutical Sciences 99 (2010)(5): 2200-2208.

[3] W. Kopaciewicz, F.E. Regnier, Nonideal size-exclusion chromatography of proteins: Effects of ph at low ionic-strength, Analytical Biochemistry 126 (1982)(1): 8-16.

[4] M. Kamberi, P. Chung, R. DeVas, L. Li, Z.J. Li, X.Y. Ma, S. Fields, C.M. Riley, Analysis of noncovalent aggregation of synthetic hpth (1-34) by size-exclusion chromatography and the importance of suppression of non-specific interactions for a precise quantitation, Journal of Chromatography B 810 (2004)(1): 151-155.

[5] G.B. Irvine, High-performance size-exclusion chromatography of polypeptides on a tsk g2000sw column in acidic mobile phases, Journal of Chromatography 404 (1987)(1): 215-222.

[6] P.L. Dubin, J.M. Principi, Optimization of size-exclusion separation of proteins on a superose column, Journal of Chromatography 479 (1989)(1): 159-164.

[7] T. Arakawa, D. Ejima, T.S. Li, J.S. Phil, The critical role of mobile phase composition in size exclusion chromatography of protein pharmaceuticals, Journal of Pharmaceutical Sciences 99 (2010)(4): 1674-1692.

[8] R. Ovalle, Nonideal size-exclusion chromatography with zwitterions causes a pi-dependent elution of proteins from glycerol propylsilane-modified silica, Analytical Biochemistry 229 (1995)(1): 1-7.

[9] G.B. Irvine, High-performance size-exclusion chromatography of peptides, Journal of Biochemical and Biophysical Methods 56 (2003)(1-3): 233-242.

[10] G.B. Irvine, Size-exclusion high-performance liquid chromatography of peptides: A review, Analytica Chimica Acta 352 (1997)(1-3): 387-397.

[11] F. Ahmed, B. Modrek, Biosep-sec-s high-performance size-exclusion chromatographic columns for proteins and peptides, Journal of Chromatography 599 (1992)(1-2): 25-33. 
[12] M.-I. Aguilar, HPLC of peptides and proteins Methods and protocols, Methods in molecular biology, 2004.

[13] K. Stulík, V. Pácaková, M. Tichá, Some potentialities and drawbacks of contemporary sizeexclusion chromatography, Journal of Biochemical and Biophysical Methods 56 (2003)(1-3): $1-13$.

[14] G.B. Irvine, C. Shaw, High-performance gel-permeation chromatography of proteins and

[15] C.T. Mant, J.M.R. Parker, R.S. Hodges, Size-exclusion high-performance liquidchromatography of peptides requirement for peptide standards to monitor column performance and non-ideal behavior, Journal of Chromatography 397 (1987): 99-112.

[17] K. Gekko, E. Ohmae, K. Kameyama, T. Takagi, Acetonitrile-protein interactions: Amino acid solubility and preferential solvation, Biochimica Et Biophysica Acta-Protein Structure and

[19] J.D. Schofield, R.C. Bottomley, M.F. Timms, M.R. Booth, The effect of heat on wheat gluten

[20] P.L. Weegels, A.M. Van De Pijpekamp, A. Graveland, R.J. Hamer, J.D. Schofield,

[21] S.M. Thanhaeuser, H. Wieser, P. Koehler, Correlation of quality parameters with the baking performance of wheat flours, Cereal Chemistry 91 (2014)(4): 333-341. Depolymerisation and re-polymerisation of wheat glutenin during dough processing 1 . Relationships between glutenin macropolymer content and quality parameters, Journal of Cereal Science 23 (1996)(2): 103-111.

I.L. Batey, R.B. Gupta, F. Macritchie, Use of size-exclusion high-performance liquidchromatography in the study of wheat-flour proteins: An improved chromatographic procedure, Cereal Chemistry 68 (1991)(2): 207-209.

3] AACC international, Methods 54-04.02, eleventh ed. AACC International, St. Paul, MN, USA, 1999. 
[24] C. Liu, H.L. Wang, Z.M. Cui, X.L. He, X.S. Wang, X.X. Zeng, H. Ma, Optimization of extraction and isolation for 11s and 7s globulins of soybean seed storage protein, Food Chemistry 102 (2007)(4): 1310-1316.

[25] AOAC, Official methods of analysis, AOAC, Washington, DC, USA, 1995.

[26] L.G. Gagliardi, C.B. Castells, C. Rafols, M. Roses, E. Bosch, Delta conversion parameter

[27] J. Léonil, V. Gagnaire, D. Molle, S. Pezennec, S. Bouhallab, Application of chromatography

[28] B.J.H. Kuipers, H. Gruppen, Prediction of molar extinction coefficients of proteins and

[29] P.L. Dubin, S.L. Edwards, M.S. Mehta, D. Tomalia, Quantitation of non-ideal behavior in

[31] N.P. Golovchenko, I.A. Kataeva, V.K. Akimenko, Analysis of ph-dependent protein

[32] D. Otzen, Protein-surfactant interactions: A tale of many states, Biochimica Et Biophysica

[33] M.N. Jones, P. Manley, Interaction between lysozyme and $n$-alkyl sulfates in aqueous 400

[35] Y. Moriyama, Y. Sato, K. Takeda, Reformation of the helical structure of bovine serum 405 albumin by the addition of small amounts of sodium dodecyl sulfate after the disruption of the structure by urea, Journal of Colloid and Interface Science 156 (1993)(2): 420-424. solution, Journal of the Chemical Society-Faraday Transactions I 76 (1980): 654-664.

4] B.J. Bennion, V. Daggett, The molecular basis for the chemical denaturation of proteins by urea, Proceedings of the National Academy of Sciences of the United States of America 100 (2003)(9): 5142-5147.

Y. Moriyama, K. Takeda, Re-formation of the helical structure of human serum albumin by the addition of small amounts of sodium dodecyl sulfate after the disruption of the structure by urea. A comparison with bovine serum albumin, Langmuir 15 (1999)(6): 2003-2008. 
410

411

412

413

414

415

416

[37] K. Takeda, Y. Moriyama, Comment on the misunderstanding of the bsa-sds complex model: Concern about publications of an impractical model, Journal of Physical Chemistry B 111 (2007)(5): 1244-1244.

[38] J.A. Huntington, P.E. Stein, Structure and properties of ovalbumin, Journal of Chromatography B 756 (2001)(1-2): 189-198. 
Table 1: Overview of used extraction/solubilizing media with their short names. Sodium dodecyl

418 sulfate (SDS) and dithiothreitol (DTT).

\begin{tabular}{ll}
\hline Extraction medium & Short name \\
\hline $\begin{array}{l}\text { Water } \\
\begin{array}{l}\text { Sodium phosphate buffer (0.050 M; pH 7.6) with 0.4 M sodium } \\
\text { chloride }\end{array}\end{array}$ & Salt medium \\
Sodium phosphate buffer (0.050 M; pH 6.8) with 2.0\% (w/v) SDS & SDS medium \\
SDS medium with $2.0 \mathrm{M}$ urea & SDS/urea medium \\
SDS medium with $1.0 \%(\mathrm{w} / \mathrm{v})$ DTT & SDS/DTT medium \\
SDS medium with $2.0 \mathrm{M}$ urea and 1.0\% (w/v) DTT & SDS/urea/DTT medium \\
\hline
\end{tabular}

Table 2. Extractability/solubility (\%) of proteins in water, salt medium, sodium dodecyl sulfate (SDS) medium and SDS/dithiothreitol (DTT) medium. Values were determined with an automated Dumas protein analysis system. Standard deviations are between brackets.

\begin{tabular}{lrrrr}
\hline & & \multicolumn{2}{c}{ SDS medium } \\
\cline { 4 - 5 } Sample & water & salt medium & & with DTT \\
\hline Bovine serum albumin & $97(0)$ & $95(4)$ & $101(1)$ & $102(2)$ \\
Ovalbumin & $103(2)$ & $96(3)$ & $103(1)$ & $104(4)$ \\
Wheat flour & $20(1)$ & $13(1)$ & $75(1)$ & $103(1)$ \\
Gluten & $20(1)$ & $14(4)$ & $81(5)$ & $100(1)$ \\
Soy glycinin & $6(1)$ & $87(4)$ & $101(2)$ & $101(2)$ \\
\hline
\end{tabular}

423

424

425

426

427

428

429

Table 3: Regression data of the calibration curves obtained by fitting the total absorbance of detected protein as a function of injected extractable protein. Bovine serum albumin, gluten and ovalbumin were extracted with sodium dodecyl sulfate (SDS) medium and separated by SE-HPLC using either acetonitrile/water $(1: 1, \mathrm{v} / \mathrm{v})$ containing $0.05 \%(\mathrm{v} / \mathrm{v})$ trifluoroacetic acid (TFA) or SDS medium as eluent. Standard deviations are between brackets.

\begin{tabular}{|c|c|c|c|c|c|}
\hline Sample & $\begin{array}{c}\text { Slope } \\
\text { (mg extracted } \\
\text { protein }^{-1} \text { ) }\end{array}$ & Intercept & $\begin{array}{c}\text { Standard } \\
\text { error }\end{array}$ & $\begin{array}{c}\text { Data } \\
\text { points* }\end{array}$ & $\begin{array}{l}\text { Linear } \\
\text { until }\end{array}$ \\
\hline \multicolumn{6}{|c|}{ Acetonitrile/water $(1: 1, \mathrm{v} / \mathrm{v})$ containing $0.05 \%(\mathrm{v} / \mathrm{v})$ TFA } \\
\hline Bovine serum albumin & $10.29(0.14)$ & $0.007(0.005)$ & 0.9949 & 19 & $0.060 \mathrm{mg}$ \\
\hline Gluten & $10.18(0.13)$ & $-0.001(0.006)$ & 0.9956 & 20 & $0.100 \mathrm{mg}$ \\
\hline Ovalbumin & $4.78(0.07)$ & $0.005(0.002)$ & 0.9957 & 15 & $0.060 \mathrm{mg}$ \\
\hline \multicolumn{6}{|c|}{ Sodium phosphate medium (0.050 M; pH 6.8) with $2.0 \%(w / v)$ SDS } \\
\hline Bovine serum albumin & $10.64(0.06)$ & $0.003(0.001)$ & 0.9995 & 12 & $0.030 \mathrm{mg}$ \\
\hline Gluten & $10.70(0.13)$ & $0.007(0.006)$ & 0.9957 & 21 & $0.100 \mathrm{mg}$ \\
\hline Ovalbumin & $10.32(0.09)$ & $0.016(0.004)$ & 0.9979 & 17 & $0.080 \mathrm{mg}$ \\
\hline
\end{tabular}

\footnotetext{
* Data points within the linear range and measured at least in triplicate
} 
Table 4. Areas of various proteins extracted with water, salt medium, sodium dodecyl sulfate (SDS)

433 medium, SDS/urea medium, SDS/dithiotreitol (DTT) medium and SDS/urea/DTT medium using 434 acetonitrile/water $(1: 1, \mathrm{v} / \mathrm{v})$ containing $0.05 \%(\mathrm{v} / \mathrm{v})$ trifluoroacetic acid as eluent. AU, arbitrary units.

435 Standard deviations are between brackets.

\begin{tabular}{lrrrrrr}
\hline & & & \multicolumn{3}{c}{ SDS medium } \\
\cline { 5 - 7 } Sample & water & salt medium & & with urea & with DTT & with urea and DTT \\
\hline Bovine serum albumin & $52(2)$ & $69(2)$ & $60(2)$ & $62(2)$ & $59(1)$ & $58(1)$ \\
Ovalbumin & $51(1)$ & $30(1)$ & $23(0)$ & $45(1)$ & $28(1)$ & $35(3)$ \\
Wheat flour & $13(0)$ & $8(0)$ & $47(1)$ & $52(0)$ & $66(0)$ & $66(1)$ \\
Gluten & $12(0)$ & $5(0)$ & $51(4)$ & $58(0)$ & $73(1)$ & $69(1)$ \\
Soy glycinin & $1(0)$ & $40(1)$ & $58(0)$ & $60(3)$ & $55(1)$ & $56(0)$ \\
\hline
\end{tabular}

436

437

438

Table 5. Relative areas of various proteins extracted with water, salt medium, sodium dodecyl sulfate (SDS) medium, SDS/urea medium and SDS/dithiothreitol (DTT) medium using SDS medium as elution solvent. Injection volume was $20 \mu \mathrm{l}$. The relative area was calculated as a percentage of the

441 corresponding peak area expressed on the area in SDS/urea/DTT medium. Standard deviations of

442 triplicates are between brackets.

\begin{tabular}{lrrrrr}
\hline & & & \multicolumn{3}{c}{ SDS medium } \\
\cline { 4 - 6 } Sample & water & salt medium & & with urea & with DTT \\
\hline Bovine serum albumin & $96(6)$ & $93(2)$ & $96(1)$ & $97(5)$ & $98(3)$ \\
Ovalbumin & $101(4)$ & $90(4)$ & $98(8)$ & $101(3)$ & $105(8)$ \\
Wheat flour & $17(0)$ & $15(1)$ & $74(2)$ & $78(2)$ & $103(5)$ \\
Gluten & $15(1)$ & $8(1)$ & $82(8)$ & $85(5)$ & $102(6)$ \\
Soy glycinin & $3(0)$ & $70(2)$ & $93(6)$ & $96(4)$ & $96(4)$ \\
\hline
\end{tabular}



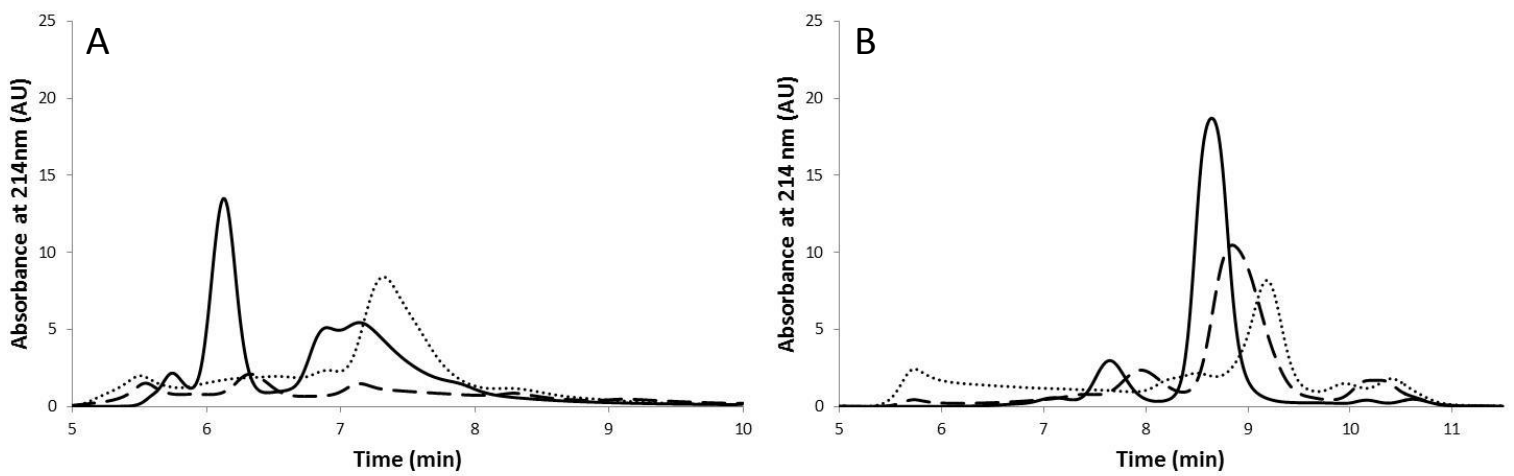

445

$95 \mathrm{kDa}$

$63 \mathrm{kDa}$

$46 \mathrm{kDa}$

$28 \mathrm{kDa}$

$15 \mathrm{kDa}$
A

$150 \mathrm{kDa}$

B

450

Figure 2. Lab-on-a-Chip capillary electrophoregram of bovine serum albumin (A) and ovalbumin (B) showing monomers and dimers of both proteins. 

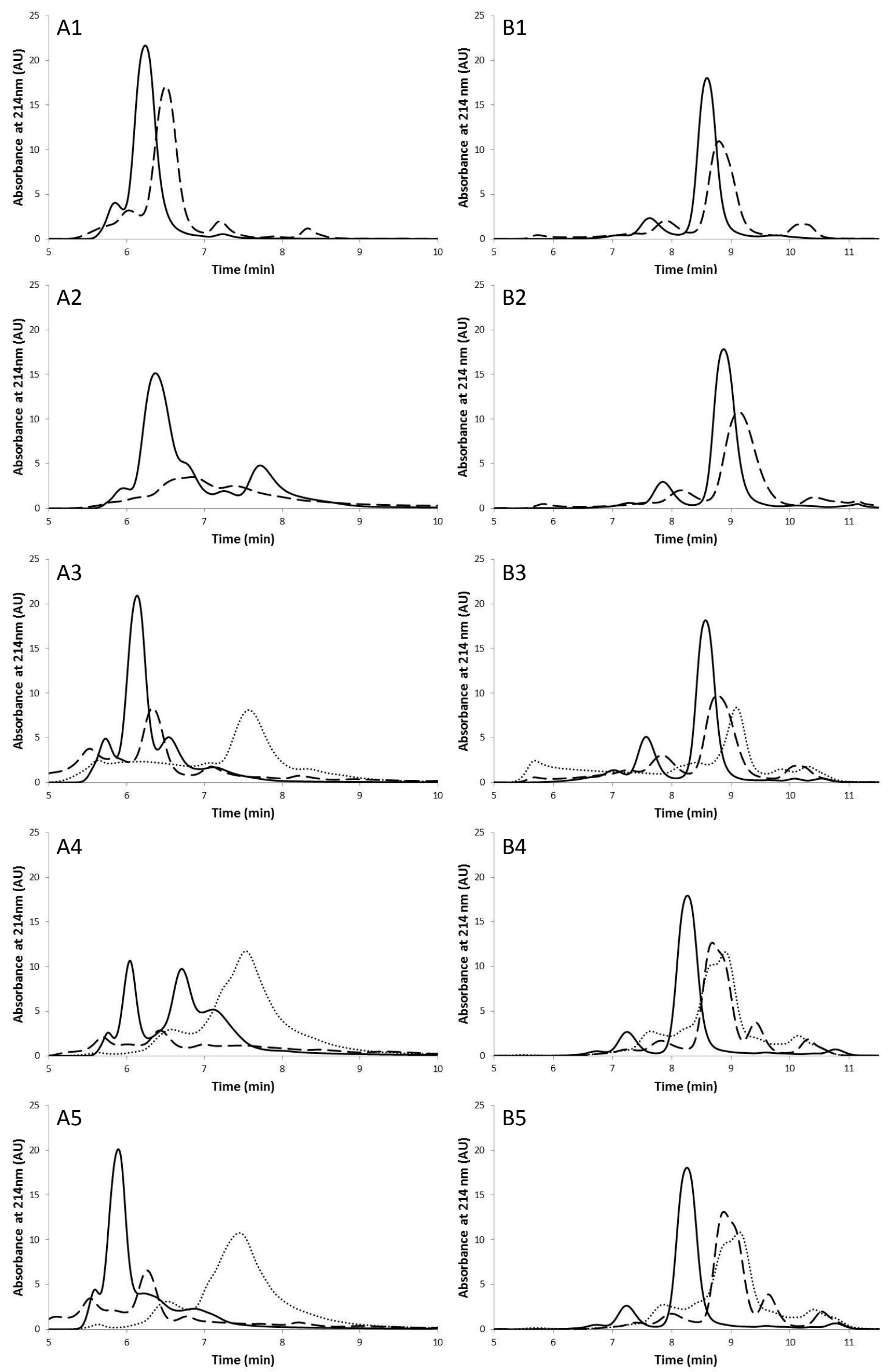
453 Figure 3. SE-HPLC profiles of bovine serum albumin (-), ovalbumin $(--)$ and gluten $(\cdots)$ for extracts 454 with water (1), salt medium (2), sodium dodecyl sulfate (SDS)/urea medium (3), SDS/dithiotreitol 455 (DTT) medium (4) and SDS/urea/DTT medium (5) using acetonitrile/water (1:1, v/v) with 0.05\% (v/v) 456 trifluoroacetic acid (A) and SDS medium (B) as eluent. AU, arbitrary units. 